(1)

GeORgE Fox

UNIVERSITY
Digital Commons @ George Fox University

Linking Theoretical Models to Actual Practices: A Survey of Teachers in Gifted Education

Danielle N. Pappas

Sheery K. Bain

Shawn J. Bourgeois 


\section{Linking Theoretical Models to Actual Practices: A Survey of Teachers in Gifted Education}

\author{
Sherry K. Bain \\ Shawn J. Bourgeois \\ Danielle N. Pappas
}

\begin{abstract}
A regional survey of teachers of gifted and talented $(G / T)$ programs, grades kindergarten through nine, in a southeastern state, was carried out. The principle foci of the survey were on theoretical models identified and used by teachers, and the importance of perceived outcome goals for children who are gifted. Respondents claimed awareness of several models of intervention but varied widely in the use of these models. Implications of the disparity between awareness and use of models are discussed. Outcome goals ranked by respondents varied in order, based on three grade level groupings of the teachers, most likely indicating changing perceptions of developmental needs as children progress through grade levels.
\end{abstract}

Sherry K. Bain is an associate professor and member of the graduate faculty in School Psychology at the University of Tennessee, Knoxville. E-mail: sbain2@utk.edu.

Shawn J. Bourgeois holds a specialist degree from Nicholls State University in Louisiana and works as a school psychologist in the Jefferson Parish School System. E-mail: shawnbourgeois@ippss.k12.la.us.

Danielle N. Pappas is a doctoral student in the School Psychology Program at University of Tennessee, Knoxville. E-mail: dpappas@utk.edu.

$\mathrm{T}$ his article reports results of a regional survey from a southeastern state, focusing on topics not typically covered in surveys of giftcd programs. Specifically, it reviews actual practices in light of familiar theoretical models for gifted and talented $(\mathrm{G} / \mathrm{T})$ programs at the kindergarten through ninth grade levels. General focus points of this survey are the identification of theoretical models of which teachers are aware, identification of models tcachers use as the bases for their programs, and the relative importance of perceived outcome goals for children who are giftcd. An cvaluation of the link between theory and practice will lead to recommendations for future training of teachers secking certification in the G/T arca. Specific focus will be on teachers of children who are intellectually gifted rather than talented, as this is the predominant assessment and placement practice in school settings among the teachers surveyed.

In introductory sections, a brief review of national, state, and regional surveys is provided, followed by a brief review of critiques of services for children who are gifted. A third section, included particularly for the reader who is new to the area of gifted education, will summarize some of the theoretical models for identification and intervention services for children who are gifted, setting a backdrop for most of the survey responses.

\section{Regional, State, and National Survey Topics}

Educational Resources Information Center (ERIC) and PsycINFO databases contain information on various state, regional, and national surveys of public school programs for children who are G/T. Early state and regional surveys focused primarily on system-level characteristics of programs for the gifted, often providing evaluation regarding expenditures, identification, and ethnic representativeness of students. Among these surveys are Renzulli and Vassar's 1967 Connecticut survey, Robbins' 1979 Ohio survey, Ezell's 1989 Arkansas survey, Lally's 1986 survey of rural Alaska, and Kalyvas's 1985 survey of two New York counties. More recent surveys were carried out by Hess (1990) in New Jersey and Belcastro (1998) in lowa.

In the last three decades, national surveys have often provided the impetus for improvement in gifted services. For instance, Marland (1972) reported to the U.S. Congress on the poor state of public school services for children who are $\mathrm{G} / \mathrm{T}$, and consequently, Mitchell (Council for Exceptional Children, 1978; Mitchell, 1984) was able to document increases in state funding allocated to gifted scrvices and a proliferation of mandated programs. Later, Colcman and Gallagher (1992) cited similar funding problems as well as problems with underrepresentation of special populations such as children who are sociocconomically disadvantaged. Again, an update (Coleman, Gallagher, \& Foster, 1994) noted improvement on these issues.

The Richardson Report (Cox, Daniel, \& Boston, 1985) provided an evaluation of the effectiveness of service delivery in its various modes. The authors noted that school-based enrichment programs, usually delivered by pull-out fashion, were the most common but least effective form. On the other hand, academic acceleration programs were the least common but most effective form. O'Connell (1986) reiterated these findings in a 15-state survey of the Appalachian region. During the same era, Houseman's 1987 national survey recorded state director's responses on items addressing policies and practices, funding, state and local services, and collaborative efforts with the public. Although Houseman did provide quantitative summaries, as well as state directors' summaries of progress and weaknesses, no overall qualitative summary was offered.

Ginally, a recent statc-wide survey by Rash and Miller (2000) endeavored to determine the day-to-day activities of teachers providing gifted services. These respondents were found to use a variety of classroom models, the four most frequently mentioned being Bloom's Taxonomy of Educational Objectives, Renzulli's Enrichment Triad, Parnes's Creative Problem Solving, and Taylor's Multiple Talent Model.

Manuscript submitted: November 1, 2002 Revision accepted: January 2, 2003 


\section{Critical Reviews of Survey Reports}

At another level, several authors have provided succinct, eye-opening critical reviews of survey results, pointing to strengths and weaknesses that predominate within an era (e.g., Gallagher, 1996; Howley, 1986; Reis, 1989). For example, Reis (1989) indicated that there is often a poor relationship between policy decisions and actual procedures for identification, as well as between policy decisions and research findings. Her conclusions raise suspicions that undocumented mismatches may occur in areas such as theoretical guidelines and actual classroom practices in gifted education.

Tn retrospect, national, state, and regional surveys of gift1 ed programs have rarely examined the match between theory and practice. While identification criteria for children who are gifted have been surveyed and discussed, the relationship of program content to the theoretical bases of giftedness is rarely explored in such surveys, with the exception of Rash and Miller's (2000) recent study. Furthermore, the perceived significance of goals among teachers in gifted programs has never been explored. Therefore, the present survey was developed to question which theoretical models were familiar to teachers, which models were the stated bases for teacher's programs, and what levels of importance teachers attribute to various goals for children who are gifted. The answers to these questions, in essence, constitute a sct of preliminary data upon which to build later enquiries into applied service models and the rationales behind them.

Differing qualitatively from most of the previously reviewed surveys, the present survey focuses on the classroom level, similar to Rash and Miller's (2000) survey, directly asking teachers about their awareness and usage of theoretical models in the classroom, along with their perceived importance of goals in gifted education. In the following section, some theoretical approaches to gifted education are briefly summarized, primarily for readers newly interested in the field of gifted education, and as an aid to interpretation of survey results.

\section{Some Theoretical Models for Gifted Education}

Although theories about educational services for individuals who are gifted might be delincated into cognitive models of intellectual giftedness and curriculum models of instruction for giftedness, in practice there is a considerable amount of conceptual overlap between the two. The broadest application of the term theoretical models is used for the purposes of this survey. The models chosen for the summary that follows were selected based on response levels in our survey and do not represent a comprehensive review of the literature on gifted education. For examples of alternative approaches, the reader might refer to Davis and Rimm (1998), Maker and Nielsen (1995), or Sternberg and Davidson (1986).

7 axonomy of Educational Objectives (Bloom and Krathwohl). This popular model links thinking and behavior skills into a hierarchy commonly used in general education. The theory includes two separate but related taxonomies: cognitive and affective. Cognitive levels (knowledge, comprehension, application, analysis, synthesis, and evaluation) and affective levels (receiving, responding, valuing, organization, and characterization by value) are linked at corresponding points so that affective and cognitive goals can be achieved simultaneously (Krathwohl, Bloom, \& Masia, 1964).

In gifted education, Bloom's taxonomy should be considered an overarching model to be generally applied to instruction in developing higher levels of thinking (e.g., analysis, syn- thesis, evaluation). Although the taxonomy model may also be useful in identifying students who are gifted, perhaps in analyzing responses on commonly used intelligence tests, evidence of practices linking the taxonomy with assessment of giftedness is difficult to find in refereed literature. On the other hand, at the intervention level, McGregor's (1994) qualitative study demonstrates that Bloom's cognitive taxonomy lends itself to the research processes often used in gifted education. Additionally, McAleer (1984) reported the use of Bloom's taxonomy to develop a talented and gifted program where students use higher order thinking skills (i.e., forccasting, hypothesizing, evaluating) to create new ideas and products.

Structure of Intellect Model (Guilford). Guilford's Structure of Intellect (SOI) represents intelligence as a multidimensional trait consisting of three interacting dimensions: an operation is performed on a particular kind of content, yielding a certain type of product. The interaction of these three dimensions, or facets and their various subcomponents, is represented in a cube-shaped model with potentially 120 separate abilities. The model represents fully-developed adult intelligence; children are typically not expected to demonstrate all of these abilities. The gifted individual, however, would possess a greater number of abilities in general or a greater magnitude or amount of specific abilities such as musical ability (Guilford, 1959).

Qeveral assessment instruments have been developed $\checkmark$ based on the SOI model. Pober (cited in Meeker \& Meeker, 1986) has used the SOI system as a screcner to establish the EAGLE program for schools in Brooklyn, New York. Application of the SOI model to intervention might include matching strengths in intellectual factors to prescribed types of activities (Guilford, 1959). However, for variety, Maker and Nielsen (1995) encourage educators to provide training in all intellectual abilities. For an applicd example of Guilford's SOI approach, see the following section on Taylor's approach.

Multiple Talent Approach (Taylor). Taylor based the Multiple Talent Approach (MTA) on aspects of Guilford's SOI model. The MTA is not hypothetically limited to children who are gifted and is suggested for developing a variety of talents in all students (Taylor, 1988). The Talents Unlimited Model demonstrates the application of the MTA in mainstream education and teaching strategies (Schlichter, 1986). Friedman and Lee (1996) offer support for the effectiveness of this model in devcloping cognitive interactions. Informal means of identification of children who are gifted follows from application of the Talents Unlimited Model across the curriculum (Schlichter).

Enrichment Triad Model (Renzulli). Renzulli's model proposes a three-pronged approach with direct application for teaching gifted students (Renzulli, 1977). Type I Enrichment focuses on general exploratory activities with the purpose of exposing students to a variety of topies not ordinarily encountered in the regular curriculum. Type II Enrichment is designed for group training in thinking and feeling processes, incorporating cognitive skills, affective training, and communication through several formats (Renzulli, 1986). Both 'Type I and Type II Enrichment activities can be incorporated into regular education classrooms. Type III Enrichment activities are specifically designed for students who are gifted. In these activities, students become researchers or scientists investigating a real problem and producing a creative product for a specific audience (Renzulli, 1986; 1999). Type III activities have been effective in developing potentials for underachieving students by capitalizing on student interests, learning styles, and positive relationships (Baum, Renzulli, \& Hébert, 1995). 
Renzulli later combined the Enrichment Triad Model with the Revolving Door Identification Model to develop the Schoolwide Enrichment Model (Renzulli \& Reis, 1994). The Revolving Door Model extends gifted services to a larger population by means of selection and advancement to higher enrichment levels according to the individual responses to opportunities provided (Renzulli \& Reis, 1986). Under this model, formal normative-based assessment of giftedness is sometimes deemed irrelevant; classroom-based performance in the program should provide relevant evidence for potential success (Reis, 1983; Renzulli \& Reis, 1994).

Autonomous Learner Model (Betts). The Autonomous Learner Model (ALM) was designed with a variety of studentoriented goals in mind. The five dimensions or levels of ALM are designed for implementation in pull-out programs to promote the development of interpersonal skills, intrapersonal skills, critical thinking skills, and responsibility (Betts, 1985). The dimensions include (a) Orientation, (b) Individual Development, (c) Enrichment Activities, (d) Seminar, and (e) InDepth Study.

Tike Renzulli's models, the ALM model does not Lspecifically address formal assessment of gifted students. However, Betts and Ncihart (1988) offer profiles of children who are gifted in six areas and include the process of identification for each area. At the intervention level, Betts (1986) has described a successful high school program that used ALM in 1978. More recent examples of ALM in practice are difficult to find in refereed journals.

Multiple Intelligences (Gardner). Gardner's Multiple Intelligences (MI) model was conceived out of his dissatisfaction with the notion of a single intelligence. The MI model outlines eight kinds of intelligence including linguistic, logicomathematical, spatial, musical, intrapersonal, interpersonal, bodily-kinesthetic, and naturalistic (Gardner, 1983; 1999). MI theory asserts that an individual's intellectual profile can be identified at a young age and that educational opportunities and options should be tailored to that profilc. The challenge for cducators is in the identification and planning of educational steps for each intellectual domain. A gifted individual or an individual with a highly advanced intelligence domain may need to work with an acknowledged master in an apprenticelike relationship and should be provided with materials he or she can explore to advance in a skill. Although Gardner offers suggestions on cducating individuals in this manner, litcraturebased application of this model in gifted education is difficult to locate among refereed sources.

Summary of theoretical models. Similarities abound Samong these models. Several (Bloom and Krathwohl's taxonomies, Renzulli's Enrichment Triad, and Betts' ALM) share a hierarchical feature, some with interrelated dimensions or facets. Several also promote the concept of many forms of intelligence or talent (e.g., Bloom and Krathwohl's taxonomies, and Gardner's MI). Approaches to identification of giftedness or talent, when addressed, vary from using specific screeners and tests (e.g., Guilford's SOI) to classroom observations of performance (e.g., Renzulli's Triad).

Recommended applications to classroom interventions also appear similar across several models; however, documentation of successful examples in the refereed literature are rare for several models. Particularly noted, also, is the scarcity of formal cfforts to link assessment to interventions, except in the case of Renzulli's and Taylor's models, which depend upon informal evaluation of success in a progression of projects and activities.

\section{Purpose of the Survey}

The purpose of this survey was to gather information, within a region of a southeastern state, regarding current training and practices in service delivery for kindergarten through ninth grade students who are gifted. Questions were framed about teachers' awareness of theoretical models for gifted education, the use of theoretical models as the bases for their programs and the relative importance of perceived outcome goals for children who are gifted. Analysis of results should lead to implications about current training of teachers for gifted programs, and about current practices. It should be noted that questions were directed more toward teachers providing services for children identified primarily as intellectually gifted, rather than talented. This was the predominant form of identification used with the surveyed group.

\section{Method}

\section{Procedure}

Following approval by the appropriate institutional review board, questionnaires were sent, through district coordinators of gifted programs or through special education directors, to teachers of gifted programs in six school distriets in a southeastern state. For the purposes of this study, which intends to focus on gifted services at the kindergarten through ninth grade levels, respondents who teach gifted classes at the tenth through twelfth grade levels only were excluded from analysis. For each school district with a total number of teachers of gifted equaling 25 or less, the number of questionnaires distributed equaled the number of teachers. For each school district whose total count of teachers of gifted was greater than 25 (two of the six districts), 25 questionnaires were distributed among teachcrs of gifted classes by the respective coordinator of gifted programs. Coordinators were asked to distribute these questionnaires randomly; no standard distribution technique was followed. Completed questionnaires were picked up at a later date by one of the researchers.

f 108 questionnaires sent or delivered, 53 were returned. One was incomplete and two respondents reported teaching only at the 10 th through 12 th grade levels; these were excluded from analysis. Answers by 50 respondents, who reported teaching at the kindergarten through 9 th grade levels, were included in the analysis. Total questionnaires returned from the six respective districts ranged from 4 to 15 .

The respondents' school districts represented four local education authorities in rural or small town regions, and two large town or suburban arcas. Total populations of students in the six participating districts, from smallest to largest, were 4,$383 ; 8,691 ; 9,946 ; 15,371 ; 32,261$; and 51,837 . Percentage of total students served as gifted ranged from $1.5 \%$ to $6.4 \%$ within the respective school districts, according to records kept by the statewide educational authority.

\section{Gifted and Talented Services Questionnaire}

The Gifted and Talented Services Questionnaire was developed by the first author with several questions in mind. Twentytwo questions were posed, most of which required information to be filled in. The first nine questions requested demographic information of the respondent, including gender, the school district where employed, total years of teaching experience, years teaching children who are gifted, state certification obtained, and university credit hours accrued in courses with content relevant to $\mathrm{G} / \mathrm{T}$ education. The second eight questions gathered information about locus and mode of services, including grade 
levels taught, number of schools served, grade levels included in the schools, student populations of schools served, number of children served as gifted in the schools, and types of program delivery (pull-out, self-contained, or other).

The respondent was then asked three questions regarding awareness and use of theorctical models or programs for children who are gifted (see Table 1, questions 18 through 20). In question 18, the term familiar was chosen to simply prompt respondents for titles and terms they have encountered in readings, coursework, and conferences without setting up an evaluation of levels of knowledge. Renzulli's Triad was offered as an example because conversations with professionals working in gifted programs indicated that this model was frequently presented at conferences and would not constitute an obscure example to confuse respondents.

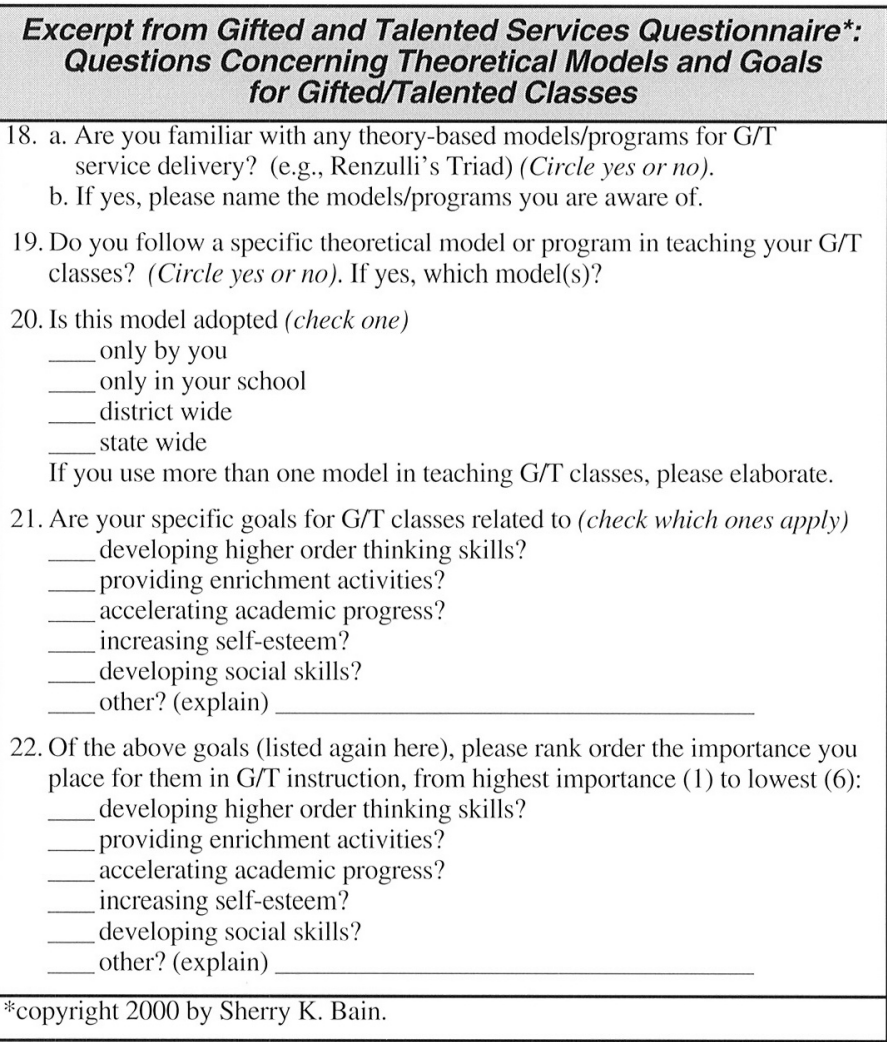

Table 1

Qinally, two questions presented respondents with a list of goals, and asked them to identily and rank goals they deemed important in gifted education (see Table I, questions 21 and 22). Additional goals could be added and ranked by the respondents. The five goals included in the questionnaire were based upon a review of the literature regarding children with special needs and children who are gifted and upon concerns voiced by teachers of children who are gifted.

\section{Results}

\section{Demographic Information}

Of the 50 respondents, 46 were female and 4 were male. All but 2 of the respondents held state endorsement for teaching children who are G/T. The number of schools in which individual teachers taught $\mathrm{G} / \mathrm{T}$ classes ranged from one to seven with grade levels ranging from kindergarten $(K)$ to nine. Total years of teaching ranged from 5 to 33 , averaging 21.6 years of teaching across respondents $(S D=6.56)$. The number of years teach- ing children who are gifted ranged from 1 to $25(M=11.78$ : $S D=6.46)$. Respondents reported total credit hours in $\mathrm{G} / \mathrm{T}$ course areas ranging from none to $39(M=15.56 ; M d n=12)$.

$\Lambda$ fter examination of the grade levels taught by responIdents, four grade level groupings were identilied for analysis of some variables. The four grade level groupings were (a) K through 6, (b) 5 through 9, (c) K through 9, and (d) 9 only. The overlap between grades 5 and 6 for the first two groups followed the self-reported levels taught by respondents.

\section{Locus and Mode of Services}

The number of gifted students served by respondents ranged from 10 to $185(M=46.27 ; S D=29.63)$. Thirty-cight respondents reported teaching children in pull-out programs, 7 reported providing services for $\mathrm{G} / \mathrm{T}$ in regular education classrooms, and 8 reported providing services in self-contained classrooms. Under the category of "other," 4 reported using combined regular education and pull-out programs; 3 reported providing enrichment activities in addition to regular classroom activities; and I reported a child being transported from the home school to the gifted teacher's base school. Gender proportions of students served were approximately $54 \%$ male and $46 \%$ female.

\section{Awareness and Use of Theoretical Models}

In response to question 18 regarding lamiliarity with theorybased models or programs for G/T service delivery (see Table 1), 49 of the 50 respondents stated "yes" in responsc to part "a," affirming that they are familiar with such models. In answer to part "b" of question 18 , the number of respondents supplying specific models of which they were aware ranged from 41

\section{Teacher's Awareness and Use of Theoretical Models for Gifted Identification and Intervention $(\mathrm{N}=50)$}

\begin{tabular}{|lcc|}
\hline Model Name & Aware of & Use in Teaching \\
\hline Betts' ALM* & $16(32 \%)$ & $6(12 \%)$ \\
Bloom \& Krathwohl's Taxonomy & $9(18 \%)$ & $5(10 \%)$ \\
Gardner's Multiple Intelligences & $14(28 \%)$ & $4(8 \%)$ \\
Guilford's SOI* & $7(14 \%)$ & $0(0 \%)$ \\
Renzulli's Revolving Door & $5(10 \%)$ & $1(2 \%)$ \\
Renzulli's SEM* & $8(16 \%)$ & $1(2 \%)$ \\
Renzulli's Triad** & $41(82 \%)$ & $12(24 \%)$ \\
Schlichter's Talents Unlimited & $2(4 \%)$ & $1(2 \%)$ \\
Torrance's Creativity Approach & $5(10 \%)$ & $1(2 \%)$ \\
\hline * ALM (Autonomous Learner Model); SOI (Structure of Intellect); \\
SEM (School Enrichment Model). \\
** Renzulli's Triad was supplied as an example on the questionnaire form.
\end{tabular}

Table 2



Figure 1. Teachers' awareness and use of $\mathrm{G} / \mathrm{T}$ models. 
(Renzulli's Triad) to 2 (Schlichter's Talents Unlimited). Other models supplied by respondents are named here as written by respondents: Betts' ALM $(n=16)$, Gardncr's Multiple Intelligences $(n=14)$, Bloom and Krathwohl's Taxonomy $(n=9)$, Renzulli's SEM ( $n=8)$, Guilford's SOI $(n=7)$, and Torrance's Creativity $(n=5)$. See Table 2 and Figure 1 for an overview of these data. Models listed by only one respondent each included Renzulli's Multi-Menu, Pirrito's Pyramid (possibly Piirto's Pyramid), Sternberg's Triarchic Theory, Such Inquiry, Purdue Enrichment, Hopkin's Acceleration, Parnes Creativity, Math for Precocious Youth, and Kaplan's Grid (again named exactly as respondents supplied them).

Q uestion 19, concerning whether respondents follow a specific theoretical model or program in teaching, was answered positively by 24 of the 50 respondents. The number of respondents stating they use specific models ranged from zero (Guilford's SOI) to 12 (Renzulli's Triad). Results are listed in Table 2 and presented graphically in Figure 1 for comparison with respondents' awareness of models. Among respondents included in the tabled results, 16 reported using combinations of models. For example, one respondent reported combining Gardner's, Renzulli's, and Betts' models; another reported using Renzulli's Enrichment Triad and Gardner's Multiple Intelligences. One respondent explained the use of six models as an effort "to reach different learning styles of students."

Only 22 respondents answered question 20 , concerning the source of adoption of the model each used. Eleven reported using models adopted by themselves; 2 used a model adopted by the school; 9 used district-wide models; and 1 reported using a statewide model (possibly addressing assessment only, as the statewide model does not mandate a particular teaching model).

\section{Goals for Gifted Programs}

Questions 21 and 22, presented in Table 1, asked respondents to check off and add to a list of specific goals that they think are important for gifted programs and next, to rank order these goals from most important to least important. Goals listed on the questionnaire, and number of respondents checking each for importance, included: (a) developing higher order thinking skills $(n=49)$; (b) providing enrichment activities $(n=48)$; (c) accelerating academic progress $(n=30)$; $(\mathrm{d})$ increasing selfesteem $(n=38)$, and (e) developing social skills $(n=35)$. Additional goals added by respondents were creativity $(n=4)$,

research $(n=4)$, computer use $(n=3)$, love of learning $(n=2)$, career awareness $(n=1)$, community mentorship $(n=1)$, compact curriculum $(n=1)$, and organization and study skills $(n=1)$.

Rankings for goals were from 1 to 5 , with 1 designating highest importance and 5 or higher (for those who added goals) designating lowest importance. Across the 50 respondents, the ranked order of prelisted goals, with mean rankings included, was higher order thinking skills $(M=1.52, n=48)$, enrichment $(M=2.67, n=48)$, acceleration $(M=3.08, n=39)$, self-esteem $(M=3.59, n=44)$, and social skills $(M=3.95, n=40)$. Creativity, a goal supplied and ranked by 4 respondents, received a mean rank of 2.75 .

Examination of the rankings with teachers in grade level groupings ( $\mathrm{K}$ through 6,5 through 9 , and 9 only) produced noted trends in ranked orders per grouping. The $\mathrm{K}$ through 6 th grade group $(n=27)$ ranked higher order thinking first, enrichment second, self-esteem third, social skills fourth, and acceleration fifth. The 5 th through 9 th grade group $(n=15)$ listed higher order thinking first, acceleration second, enrichment third, self-esteem fourth, and social skills fifth. The teachers of
Mean Rankings (and Order) of Five Goals for Gifted Programs

According to Teacher From Three Grade Level Groupings*

Grade Level Groupings of Teachers

\begin{tabular}{llll} 
Goal & K through 6 & 5 through 9 & 9 only \\
\hline Higher Order & $1.62(1)$ & $1.38(1)$ & 1.67 (tied for 1$)$ \\
Thinking Skills & $n=26$ & $n=13$ & $n=6$ \\
Enrichment & $2.46(2)$ & $2.77(3)$ & 3.67 (tied for 2$)$ \\
Activities & $n=26$ & $n=13$ & $n=6$ \\
Acceleration & $3.70(5)$ & $2.50(2)$ & 1.67 (tied for 1$)$ \\
& $n=20$ & $n=10$ & $n=6$ \\
Self-Esteem & $3.48(3)$ & $3.60(4)$ & 3.67 (tied for 2$)$ \\
& $n=25$ & $n=10$ & $n=6$ \\
Social Skills & $3.57(4)$ & $4.22(5)$ & $4.40(3)$ \\
& $n=23$ & $n=9$ & $n=5$ \\
\hline
\end{tabular}

*Three teachers fell in a broad grade-level grouping of $\mathrm{K}$ through 9; because of the small number, this group was included in the total analysis (see text for results), but group means were not calculated.

\section{Table 3}

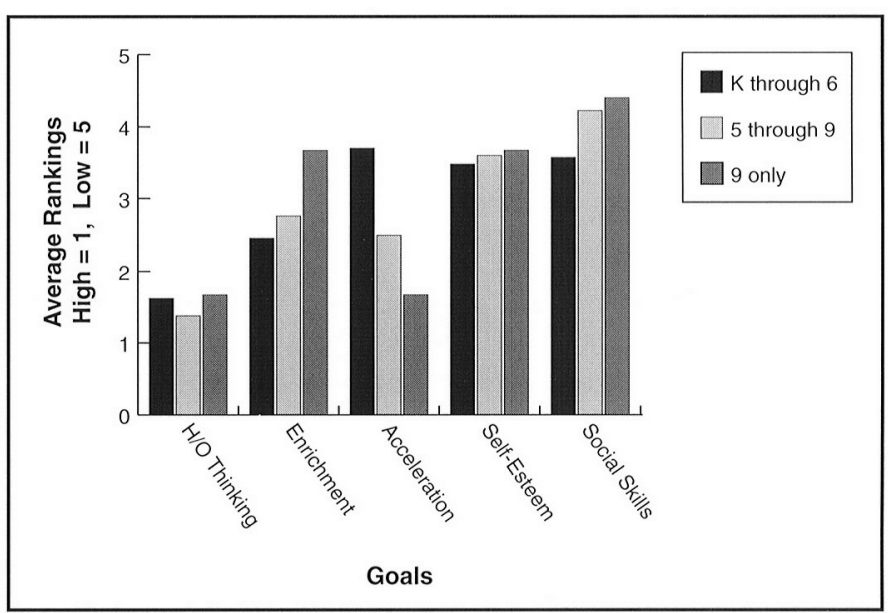

Figure 2. Teachers' mean rankings of five goals ( 1 = highest importance, $\mathbf{5}$ = lowest importance) among three teaching levels.

9 th grade only $(n=6)$ tied higher order thinking and acceleration in first place, enrichment and self-esteem in second place, and ranked social skills last. Results of these findings are displayed in Table 3 and Figure 2. The remaining group ( $\mathrm{K}$ through 9), represented by only 3 respondents, ranked goals identical to the ranked order across 50 respondents.

\section{Discussion and Conclusion}

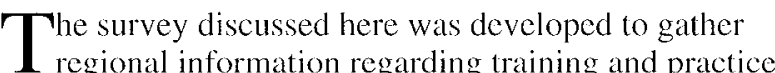
in service delivery for $\mathrm{K}$ through 9 th grade students who are gifted. The primary objectives were to obtain information about teachers' awareness of theoretical models for gifted education, their use of theoretical models as the bases of their programs, and the relative importance of outcome goals in gifted programs. Results constitute an initial probe into issues rarely addressed by state, regional, and national surveys found in the literature on gifted education.

In general, respondents stated familiarity with at least one or more theory-based models for gifted identification or education. The greatest number of respondents claimed familiarity with Renzulli's Triad, the example provided on the questionnaire. However, several other models were supplied by respondents, with eight additional models garnering mention by two or more respondents. 
A comparison of models identified and models actually used by respondents reveals a far from tidy match between respondents' awareness of programs and their use in classrooms. Twelve of the 41 teachers claiming awareness of Renzulli's Triad, which was supplied as an example on the questionnaire, also claimed that they use that model in the classroom. The largest ratio of use to awareness of a model was for Bloom's Taxonomy (5:9), probably representing application of Bloom's model as an overarching principle rather than a prescribed curriculum. Betts' Autonomous Learner Model garnered a ratio of 6 who use the model to 16 aware of it, followed by Gardner's Multiple Intelligences (4:14). The number of respondents claiming to use the model identified as Renzulli's Triad most likely attests as much to the widespread dissemination of this model as to the fact that the name was provided as an example on the questionnaire.

The teachers' propensities to name more models than they might practically be able to apply in practice is reasonable, since they were simply asked to identify models, not to supply details of the models. However, the application of models to classroom practices fell at an unexpectedly modest rate. Approximately half of the respondents failed to identify usage of any model their classrooms, leaving unanswered questions about foundations that underlay their instruction. The survey did not include items that explored the mismatch between awareness of models and usage of models, such as what prompts teachers to select models. Therefore, only assumptions can be made about the nature of the responses. One such assumption is that while the teachers are cager to declare familiarity with models in their field of gifted education, they are also characteristically honest about their actual practices. How the lack of theoretical application in the classroom might adversely affect teaching practices in gifted education should be a central issue explored in the accountability domain.

$\mathrm{R}$ ash and Miller (2000), who supplied a list of teaching models to their survey respondents, reported more frequent usage of teaching models than we found. Eighty-seven percent of their respondents claimed to use Bloom's Taxonomy, followed in descending order by Renzulli's Triad (65\%), Parnes Creative Problem Solving (63\%), and Taylor's Multiple Talents $(48 \%)$. Several other models garnered a smaller percentage of reported use by respondents. The frequency of use of theoretical models across respondents in the present study began at $24 \%$ claiming to use Renzulli's Triad, with a sharply declining percentage of the total designating other models (see Table 2).

The contrast between the results of the present study and those of Rash and Miller are striking and raise questions about survey methodology and interpretation of results. First, what effect does the actual listing of teaching models on the questionnaire itself have on results? Is there a readiness on the part of respondents to supply socially approved responses by checking several choices? On the other hand, what effect does asking the respondent to supply the model by name, as in the present study, have on the validity of results? Hopefully, this method increases the validity of responses. Future surveys might be designed to ferret out socially desirable responses by including brief scales measuring social desirability. Qualitative investigations might ask teachers to supply elements of evidence in the form of lesson plans that incorporate use of various theories to confirm actual practices.

A second question raised concerning practices in the present study and Rash and Miller's study is the validity of claims that some teachers apply multiple models in their classrooms. Rash and Miller's results, in terms of percentages of respondents fol- lowing each model, indicate that many teachers follow multiple models. Several respondents in the current study claim multiple model usage. It is possible, even probable, that some theoretical models may not lend themselves universally to compatible pairing with other models in a single classroom. Investigations into compatibility of theoretical models might incorporate quantitative surveys of stated practices with qualitative examinations of compatibility of models in programs for the gifted and talented.

When asked if they follow a specific theoretical model, 26 of the 50 respondents in the present study stated "no." This result leads to questions about the quality of programs in nearly half of the service delivery venues among the teachers surveyed. They also raise concerns regarding the adequacy of specialized training for gifted education. Is the match between theory and practice emphasized in courses and in continuing education opportunities? If so, why is this not reflected in the survey results? Is program accountability lax across school districts? Is the training for endorsement for teaching in the gifted area too short, too cursory? Is funding for training and program implementation adequate to mect the needs of children who are gifted? A portion of these issues have been addressed somewhat generically in past surveys, comparing expenditures and practices across time but not necessarily matching specific practice issues with training needs. Future studies, particularly surveys of a more microscopic nature that focus on specific training programs and needs paired with the actual practices of teachers, might scek to answer some of these questions.

The second major objective addressed by this survey is the selection and ranking of program goals appropriate for children who are gifted. Survey results may be somewhat confounded

\section{When asked if they follow a specific theoretical model, 26 of the 50 respondents in the present study stated "no." This result leads to questions about the quality of programs in nearly half of the service delivery venues among the teachers surveyed.}

by the presupplied order of suggested goals. Nevertheless, teachers' rankings of the supplied goals varied across grade level groupings of respondents, likely indicating trends in needs as children mature. Specifically, grade level groupings of teachers ranked higher order thinking skills as having the highest importance, but varied in ordering enrichment, acceleration, self-esteem, and social skills. Acceleration as a goal was not as strongly valued among teachers of the earlier grade levels as among teachers of the middle school and junior high levels. For teachers at the $\mathrm{K}$ through 6 th grade level, enrichment placed second to higher order thinking skills, cchoing findings from the Richardson Report defining actual practices. One has to note that the trend favoring enrichment continues, based upon current results, despite contrary recommendations from the Richardson Report (Cox, Daniel, \& Boston, 1985).

The teachers' ranking of goals, if considered valid, is a fair representation of predominant practices, as declared in their usage of theoretical models. Betts' ALM, Bloom and Krathwohl's Taxonomy, and Renzulli's Triad, used by several of the respondents, directly address the highest rated goal of higher 
order thinking to a strong degree. Remaining theoretical approaches named and used by a few respondents (Torrance, Gardner, and Taylor) center more upon a multiple talent approach or on creative (productive thinking) activities. Ironically, selcction of students was typically made based upon a combination of parent/teacher recommendations and intellectual and academic performance, with measures of creativity weighing in as an alternative method, if needed, based upon state guidelines for identification and placement.

Because the number of respondents in each grade level group was rather small, ranging from 6 to 26 respondents per group, responses from additional teachers across grade levels and geographic regions will provide validation for these grade level rankings of goals and confirm suspected trends in perception of needs across developmental levels. Redesigning the survey form by varying the order of proposed goals across alternate forms and adding some additional goals, such as creativity or divergent thinking skills, will provide additional information about perceived goals for gifted education.

$\mathrm{P}$ ractical implications from this study apply principally to the training of teachers for gifted programs and to policy management at the local and state levels. University educators involved in training teachers for gifted programs should note the lack of consistent importance given to matching theoretical models to actual practice. Increased attention should be given to teachers' critical thinking skills related to the issues of documented effectiveness of interventions. Local and state education authorities should consider these same topics for continuing education training. In addition, these agencies would be well advised to give consideration to the benefits of mandating, or at least sanctioning, well-documented programs in providing services for the gifted.

In terms of future efforts to survey practices in G/T programs, researchers at the local, state, and national levels are encouraged to gather information beyond levels of funding and quantification of serviees. Ineluding the fit between theory and practice, as well as the adequacy of training models for applied practice, will add an evaluative level appropriate to the area of gifted education.

In summary, responses from this study represent a geo1 graphic region of rural, small town, and suburban schools within a southeastern state. Although not a random sample, an adequate return rate of the questionnaires across several school districts is believed to provide a fair representation of the range and limits of practices in this region. Future surveys probing the topics of awareness and usage of theoretical models, as well as goals decmed appropriate for educating children who are gifted, should provide information about the generalizability of these results across geographic regions and states.

\section{REFERENCES}

Baum, S. M., Remzulli, J. S., \& Hébert, T. P. (1995). Reversing underachievement: Creative productivily as a systematic intervention. Ciffed child Quarterly, 39, 224-235.

Belcastro, F, P. (1008). A survey of types of giffed programs offered in lowa Public School Districts. Dubucue, IA: University of Dubuque. (ERIC Document Reproduction Services No. ED432110)

Belts, (3. T. (1985). Autonomous learner model: For the gifted and ialented. Grecley, CO: Autonomous Learner Publications and Specialists.

Betts, G. T. (1986). The autonomous learner model for the gifted and talented. In J. S. Remalli (lid.), Systems and models gor developing programs for the giffed and talentcd (pp. 27-56). Mansfield Center, CT: Creative L carning Press.

Betts, (i. T., \& Neihart, M. (1988). Profiles of the gifted and talented. Cifted Child Quartcrly, 32, 248-253

Coleman, M. R., \& Gallagher, 3. (1992). Report on stane policies related to the idemificasion of giffed students. Chapel Hlill, NC: North Carolina University. (ERIC Document Reproduction Services No. ED344368)

Coleman, M. R., Gallagher, J., \& Foster, A. (1994). Updated report on state policies related to the itemification of giffed students. Chapet Hill, NC: North Carolina Unjversity. (ERIC Document Reproduction Services No. ED372591)
Council for Exceptional Children (1978). The nation's commitment the education of gifled and lalented children and youh: A summary of findings from a 1977 survey of states and territories. Reston, VA: Council for Exceptional Children. (IERIC Document Reproduction Services No. ED155829)

Cox, J., Danicl, N., \& Boston, B. (1985). Ldacating able learners: Programs and promising pracices. Austin, TX: University of Texas Press.

Davis, G. A., \& Rimm, S. B. (1998). Education of the gifted and talented. (4th ed.). Needham Heights, MA: Allyn \& Bacon.

Ezell, J. M. (1989). A survey of kindergarten-sixth grade gifted/alented programs in the state of Arkansas for 1987.1988 (sixth grade) (Doctoral dissertation, University of Arkansals, 1989). Dissertation Abstracts Interndtional, 50, 1936. (UMJ No. AAG 89-25696)

Fricdman, R., \& Lee, S. (1996). Differentiating instruction for high-achieving/gifted children in the regular classrooms: A ficld test of three gifted-education models. Journal for the Edacation of the Gifted, 19, 405-436.

Gallagher, J. J. (1996). A critique of critiques of gifted cducation. Joumal for the Laducation of the Gifted, 19, 234-249.

Gardnet, H. (1983). Frames of mind: The theory of mulliple intelligences. New York: Basic Books.

Gardner, H. (1999). Are there additional intelligences? The case for naturalist, spirituat, and existential intelligences. In J. Kane (Ed.), Lducation, information, and tramsformation: Essays on learning and thinking (pp. 11 1-131). Upper Saddle River, NJ: Merrill.

Guilford, J. P. (1959). Three faces of intellect. The American Psychologist, 14, 469-479.

Hess, K. K. (1900). The status of gifted education in New Jersey: Analysis of the I988-80 Gifled Laducation Survey. Trenton, NJ: Now Jersey State Department of Education. (ERIC Document Reproduction Services No. ED432110)

Houseman, W. (1987). The 1987 state of the suttes gifted and talemed educatom report. Helena, MT: Council of State Directors of Programs for the Gificd. (IERIC. Document Reproduction Services No. ED295406)

Howley, C. B. (1986). Imellectually gifled sundems: Issues and policy implications, policy issucs. Charleston, WV: Appalachia Education Laboratory. (ERIC Document Reproduction Services No. ED296569)

Kalyvas, M. (1985). A survey of talented and gifted programs for elementary school students in Nassau and Suffolk counties, New York (Doctoral dissertation, Columbia University Teachers College, 1985). Dissertation Abstracts Inernational, 40, 2560. (UMI No. AAG $85-25479$ )

Krathwohl, D. R., Bloom, B. S., \& Masia, B. B. (1964). Taxonomy of educuriomal objec tives. New York: David McKay.

Lally, E. M. (1980). A survey of gifted program administration in rual Alaska (Doctoral dissertation, University of the Pacific, 1986). Dissertation Abstracts Imernational, 50, 3625 . (UMI NO. AAC $87-12100)$

Maker, C. J., \& Nielsen. A. B. (1995). Teaching models in edacarom of the giffed. Austin, TX: Pro-Fd.

Marland, S. P., Jr. (1972). Elucation of the gifted and talented. Report to the ("ongress of dhe United States by dhe Commissioner of tidacation. Washington: U.S. Covernment Printing Office.

MeAlecr. F. F. (1984). TJE-ing it together for our gilted soudents: The 'TIF: challenge. Rocper Reiven: 7, $111-113$.

MeGregor, J. H. ( 1994 ). Cognitive processes and the use of information: A qualitative study of higher order thinking skills used in the research process by students in a gitied program. Soloel Libromy Media Anmul, 12, 124-1.33.

Mecker. M. \& Mecker, R. (1986). The SOI system for gifted cducation. In J. S. Renzulli (Ed.), Systems and models for developing programs for the gifted and alemed (pp. 194-215). Mansficld Conter, ("T: Creative leaming Press.

Mitchell, B. M. (1984). An update on gifledtalented celucation in the U.S. Rosper Reviest. $0,161-163$

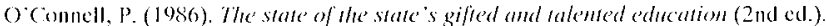
Augustit. MN: Mitine State Department of liducational and Cultural Services. (I:RIC Document Reproduction Services No. ED288.43)

Rash, P. K. \& Miller, A. D. (2000). A survey of pritelices of teachers of gifted Roeper Reliew, 22, 192-194.

Reis, S. M. (1983). Creating ownership in giffed and talented prograns. Reeper Review $5(4), 20-23$.

Reis, S. M. (1989). Reflections on policy affecting the education of gifted and alented students: Past and future perspectives. American Psychologist, 47, 399-408.

Renzulli, J. S. (1977). The emrichment triad model: A giride for developing defensible programs for the gifted and lalemed. Wethersfield, Cl: Creative learning Press.

Renzulli, J. S. (1986). The three-ring conception of giftedness: A developmental model for creative productivity. In R. J. Stermberg \& J. L. Davidson (Eds.), Conceptions of giffedness (pp. 53-92). New York: Cambridge University Press.

Renzulli, J. S. (1999). What is this thing called giftedness, and how do we develop it? A twenty-five year perspective. formal for the lidecation of the (iiffed, 23, 3-54.

Renzulli, J. S., \& Reis, S, M. (1986). The enrichment triad/revolving door model: $A$ schoolwide plan for the development of creative productivity. In J. S. Renzulli (Ed.), Systems and models for developing programs for the gifted and valened (pp. 216266). Mansficld Center, C7: Creative Learning Press.

Renzulli, J. S., \& Reis, S. M. (1994). Rescarch related to the schoolwide enrichment triad model. (;iffed Child Quarterly, 39, 7-20.

Renzulli, J. S., \& Vassar, W. G. (1967). The gifted child in Comecticul, a survey of programs. Hartford, CN: Connecticut State Department of Education. (LRIC: Document Reproduction Services No. EDOO2341)

Robhins, A. L. (1979). A survey of Ohio public school programs for gifted and talented students (K-8). (Doctoral disscration, Miami University, 1979). Dissertation Abstracts liternational, 4l, 0204. (UMI No. AAG 80 13438)

Schlichter, C. L. (1986). Talents unlimited: $A_{n}$ inservice education model for teaching thinking skills. Giffed Child Quarterly, 30, 119-123.

Sternberg, R. J., \& Davidson, 3. E. (Eds.). (1986). Conceptions of gifiedness. New York Cambridge University Press.

Taylor, C. W. (1988). Various approaches to and definitions of ereativity. In R. J. Stern berg (Ed.), The nature of creativity (pp. 99-123). New York: Cambridge University Press. 